\title{
Why I Like Being an Academic Psychiatrist
}

\author{
Rahn Kennedy Bailey
}

Received: 27 June 2013 / Accepted: 22 July 2013 / Published online: 19 March 2014

(C) Academic Psychiatry 2014

Keywords Academic careers · Psychiatric education · Administration

What I like about academic psychiatry is its broadness and diversity. It keeps me energized and creative. I am inspired by all aspects of my career, including medical education, advancement of knowledge through research, clinical care, promoting professionalism, supervision, and administration. University-oriented work enables me to conduct scientific investigation and develop innovative educational interventions, while still engaging with clinical psychiatric practice.

Academic psychiatry embraces a broad-based and longitudinal approach that requires strong clinical skills, research skills, and scientific inquisitiveness. Education is an important element of academic psychiatry. It is a great privilege to teach future doctors the vital psychiatric skills to help shape them into our future physicians. It is very fulfilling to me knowing that my enthusiasm may inspire students and residents to come to embrace the wonder of psychiatry.
Psychiatry is a rapidly changing specialty that requires physicians to keep current with recent advances in medical behavior and social science. My profession provides me the opportunity to pursue both the advancement of knowledge and my own intellectual and scholarly interests. It translates research findings into sustainable improvements in clinical practice. As leaders in medicine, we reserve time to collaborate with clinical and academic colleagues throughout the country by professional exchange. It allows me to extend the clinical caring to underserved and disadvantaged communities without the primary concern of their financial ability to pay. It gives me the opportunity to serve the community by promoting public health and policy decision-making.

Overall, I love my work as a chairman of a department of psychiatry. Few other working environments provide such flexibility and professional freedom for me to perform such good works for others.

Disclosure The author has no conflicts of interest to disclose in relation to this perspective piece.

R. K. Bailey $(\bowtie)$

Meharry Medical College, Nashville, TN, USA

e-mail: rkbailey@mmc.edu 